\title{
Additives, Hole Transporting Materials and Spectroscopic Methods to Characterize the Properties of Perovskite Films
}

\author{
Amita Ummadisingua, Ji-Youn Seo , Marko Stojanovic ${ }^{a}$, Shaik M. Zakeeruddina, Michael Grätzela, \\ Anders Hagfeldt ${ }^{\mathrm{b}}$, Nick Vlachopoulos ${ }^{\star \mathrm{b}}$, and Michael Saliba ${ }^{* a}$
}

\begin{abstract}
The achievement of high efficiency and high stability in perovskite solar cells (PSCs) requires optimal selection and evaluation of the various components. After a brief introduction to the perovskite materials and their historical evolution, the first part is devoted to the hole transporting material (HTM), between photoelectrode and dark counter electrode. The basic requirements for an efficient HTM are stated. Subsequently, the most used HTM, spiro-OMeTAD, is compared to alternative HTMs, both small-molecule size species and electronically conducting polymers. The second part is devoted to additives related to the performance of the perovskite light-absorbing material itself. These are related either to the modification of the composition of the material itself or to the optimization of the morphology during the perovskite preparation stage, and their effect is in the enhancement of the power conversion efficiency, the long-term stability, or the reproducibility of the properties of the PSCs. Finally, a number of spectroscopic methods based on the UV-Vis part of the electromagnetic spectrum useful for characterizing the different perovskite material types are described in the last part of this review.
\end{abstract}

Keywords: Crystal engineering · Hole conductor · Perovskite solar cell · Solar cell efficiency ·

Photoluminescence spectroscopy

\section{Introduction}

The latest perovskite solar cell (PSC) world record in terms of power conversion efficiency (PCE) is $22.1 \%$. $^{[1]}$ This is an astounding feat since PSCs started off with a mere $3.8 \%$ PCE in 2009 as demonstrated by Miyasaka and co-workers. ${ }^{[2]}$

Perovskites are all materials that adhere to an $\mathrm{ABX}_{3}$ lattice. For photovoltaics, this is typically $\mathrm{A}=(\mathrm{Rb}, \mathrm{Cs}$, methylammonium (MA), or formamidinium (FA)); $\mathrm{B}=\mathrm{Pb}$ or $\mathrm{Sn}$; and $\mathrm{X}=(\mathrm{Cl}, \mathrm{Br}$, or $\mathrm{I})$.

Interestingly, the latest boom for photovoltaics is based on much earlier research. Already in 1978, Weber synthesized

${ }^{\star}$ Correspondence: Dr. N. Vlachopoulos ${ }^{b}$, Dr. M. Saliba ${ }^{a}$ E-mail: nikolaos.vlachopoulos@epfl.ch, michael.saliba@epfl.ch

aLaboratory of Photonics and Interfaces and bLaboratory of Photomolecular Science École Polytechnique Fédérale de Lausanne Laboratory of Photomolecular Science Institute of Chemical Sciences and Engineering EPFL-FSB-ISIC-LSPM

Chemin des Alambics, Station 6

$\mathrm{CH}-1015$ Lausanne
$\mathrm{MAPbX}_{3}$ and $\mathrm{MASnX}_{3}$ crystals, describing the semiconducting and metallic character, respectively. ${ }^{[3,4]}$ The molecular cation MA in these compounds is sufficiently small to fit in the gaps of the interconnecting metal halide octahedra $\left(\mathrm{PbX}_{6}\right)$, which are therefore denoted as '3D perovskites' .

The hybrid organic-inorganic perovskite materials were then investigated further using larger molecular cations than MA resulting in distinct organic and inorganic layers where the metal halide octahedral no longer interconnects. Such structures are denoted as '2D perovskites'. These compounds are multiple quantum well systems with remarkable optical properties ${ }^{[5-10]}$ showing, for example, biexcitonic lasing. ${ }^{[11]}$ First applications were reported in 1999 by Mitzi and co-workers who demonstrated thin-film field-effect transistors using a $\left(\mathrm{C}_{6} \mathrm{H}_{5} \mathrm{C}_{2} \mathrm{H}_{4} \mathrm{NH}_{3}\right)_{2} \mathrm{SnI}_{4}$ perovskite. [12] However, such 2D perovskites often have high excitonic binding energies that can hamper charge separation and are sensitive to moisture as well as oxygen (especially when using $\mathrm{Sn}(\mathrm{II}))^{[10]}$

It was only in 2009, as mentioned above, that 3D perovskites, mainly $\mathrm{MAPbX}_{3}$, were revisited as the absorber materials in dye-sensitized solar cells (DSSCs). ${ }^{[2,13]}$ This concept was later extended towards solid-state DSSCs where the electrolyte was replaced by the small molecule hole-transporter material (HTM) 2,2,9,7,7,9-tetrakis(N,N di-p-methoxyphenyl-amine)9,9,9-spirobifluorene, commonly named spiro-OMeTAD. [14] Subsequently, Snaith and co-workers demonstrated that perovskite solar cells can also work on an insulating $\mathrm{Al}_{2} \mathrm{O}_{3}$ or no meso-scaffold at all showing the semiconducting nature of PSCs. ${ }^{[15,16]}$ The development of PSCs has been very rapid since with major advances in efficiency and stability as outlined in a number of reviews, e.g. by Calió et al., ${ }^{[17]}$ Gao et al., ${ }^{[18]}$ Gottesman et al., ${ }^{[19]}$ Green et al., ${ }^{[20]}$ Marinova et al., ${ }^{[21]}$ Miyasaka et al., ${ }^{[22,23]}$ Singh et al., ${ }^{[24]}$ Snaith et al., ${ }^{[25]}$ Stranks et al., ${ }^{[26]}$ Correa-Baena et al., ${ }^{[27]}$ and Saliba et al. ${ }^{[28]}$

In this review, a survey is provided of the different HTMs that have been explored for PSCs in recent years. Additionally, some major advances on additive-engineering of the perovskite layer itself are presented. Finally, a summary is provided of the basic characterisation methods that have been used to analyse perovskite thin films.

\section{Hole Transporting Materials}

In a PSC the hole-electron pair generated in the absorbing layer is separated by the electron-transporter material and the HTM. Once the hole has been transferred to the conducting material, it will diffuse to the back electrode so as to close the circuit. HTMs can be separated into two main categories: inorganic ${ }^{[29]}$ and organic. ${ }^{[30]}$ Here, the focus is mainly devoted on the 
larger group of organic HTMs, which can be further divided in two main sub-categories, depending on the nature of the material: polymers ${ }^{[31]}$ and small molecules. ${ }^{[32]}$ The conducting properties of HTMs are often enhanced by adding small amounts of dopant, thereby providing yet another division into dopant ${ }^{[33]}$ and dopant-free ${ }^{[34]}$ HTMs (Fig. 1).

In general, HTMs play an important role for the device performance and need to fulfil several requirements to provide high efficiency PSCs. Firstly, they have to show high charge mobility, ideally above $10^{-3} \mathrm{~cm}^{2}(\mathrm{~V} \times \mathrm{s})^{-1}$ for holes. ${ }^{[35]}$ In addition, they should have little absorption in the vis-IR region to avoid overlap with the perovskite layer. This is especially important for tandem and semi-transparent architectures. Finally, HTMs should also have a glass transition temperature $\left(\mathrm{T}_{\mathrm{q}}\right)$ above $85^{\circ} \mathrm{C}$ to ensure long-term stability of the PSC that needs to withstand temperatures up to $85^{\circ} \mathrm{C}$. To be compatible with device fabrication, HTMs need to be easily processed through solution-based techniques. Regarding band alignment, the HOMO level of the HTM should be higher in energy than the valence band of the perovskite absorber to ensure efficient operation of the device. ${ }^{[17]}$

Each of these previously listed properties can be addressed to some extent through rational engineering of the molecular HTM structure. For example, the use of spirofluorene type structures has proven to be beneficial for increasing $\mathrm{T}_{\mathrm{g}} .{ }^{[36,37]}$ The energetics are usually tuned by the electronic properties of the substituents present in the molecule. The charge mobility can be optimized by using electron-rich building blocks such as aryl amines and fluorenes, ensuring good electronic conjugation and compatibility along the molecule or the polymer.

These structures are frequently synthesized using palladium-catalysed cross coupling chemistry such as the Suzuki reaction, the Stille reaction, or BuchwaldHartwig reaction. The reaction uses an organo-halide precursor and an organometallic partner combined with a suitable palladium(0)-phosphine catalyst. ${ }^{[38]}$ More recently, efforts have been put into developing milder and more environmental friendly synthetic methods, the so-called direct $\mathrm{C}-\mathrm{H}$ arylation, which does not require any toxic and sometimes very reactive organometallic coupling partners. [39]

One of the most used HTMs is the aforementioned spiro-OMeTAD. Its core consists of two fused fluorenes resulting in a molecule with a twisted shape and a relatively high $\mathrm{T}_{\mathrm{g}}$ of $125^{\circ} \mathrm{C} .{ }^{[40]}$ This HTM has resulted in some of the highest efficiencies for PSCs and is also an efficient charge carrier in solid-state dye sensitized solar cells. ${ }^{[41,42]}$ Despite popular usage, spiro-OMeTAD shows notable drawbacks such as a rather long and low-yielding synthesis, a low hole mobility of about $1.6 \times 10^{-4} \mathrm{~cm}^{2}(\mathrm{~V} \times \mathrm{s})^{-1}$. Nevertheless, Snaith et al. reported in 2016 that hole mobility can be increased by a factor of 10 using lithium doping. ${ }^{[43]}$

There is now an urgent need to develop new HTMs that could be synthesized easily and ideally work efficiently under dopant-free conditions, which could improve device stability and increase reproducibility. ${ }^{[33]}$

Much progress has been made in recent years towards this goal. For example, Zhao et al. developed a one-step synthesis of a dopant-free HTM with a $\mathrm{T}_{\mathrm{o}}$ of $100{ }^{\circ} \mathrm{C}$ giving an impressive PCE of $15.4 \%$ and good stability. ${ }^{[44]}$ In $2016 \mathrm{Xu}$ et al. presented a low cost HTM containing as a core spiro[fluorene-9,90-xanthene] with a hole mobility of $1.9 \times 10^{-4} \mathrm{~cm}^{2}(\mathrm{~V} \times \mathrm{s})^{-1}$ resulting in PCEs of up to $19.84 \%$ (still using dopants). ${ }^{[45]}$ In the same year, Krishna et al. demonstrated a silafluorene bearing arylamines moieties using a one-step reaction. This resulted in PCEs of 11\%.[46]

As outlined in Fig. 1, among the possible candidates that can replace spiro-OMeTAD are diketopyrrolopyrole (DPP)-based organic semi-conductors. ${ }^{[47]}$ Recently, this class of compounds exhibited impressive hole mobilities of above $10 \mathrm{~cm}^{2}(\mathrm{~V} \times \mathrm{s})^{-1}$, mainly in organic field effect transistors as polymers. ${ }^{[48]}$ This material has now been used for PSCs as building block for both small molecule and polymers. Last year, Liu et al. reported the synthesis of a OMeTPA-DPP small molecule HTM, which showed a very good $\mathrm{T}_{\mathrm{g}}$ of $157^{\circ} \mathrm{C}$, with relatively low PCEs of
$8.69 \%$ but without dopants.[49] ThienylDPP was used in a polymer by Dubey et al. in 2016. They reported the synthesis of PDPP3T producing a PCE of $12.3 \%$ without dopant which showed good stability. ${ }^{[50]}$ On the other hand, the main drawbacks associated with DPP molecules is the strong colour they may have as well as processing issues, as this type of compounds are known to aggregate very easily due to their strong planarity.

In addition, efficient organic polymers have been developed for dopant-free PSCs. Liao et al. reported the synthesis of a polymeric HTM based on the 4,8-dithien2-yl-benzo[1,2-d;4,5-d']bistriazole-altbenzo[1,2-b:4,5-b']dithiophene monomer structure (pBBTa-BDTs), which produced a stable PCE of $12.3 \%$ and hole mobility around $1.5 \times 10^{-3} \mathrm{~cm}^{2}(\mathrm{~V} \times \mathrm{s})^{-1}$. ${ }^{[51]}$

\section{Additives in the Perovskite Formation Process}

One simple way to modify the material properties is the purposeful addition of small amounts of new substances, i.e. 'additives', into the existing systems. Such additive engineering has been applied to perovskite solar cells to enhance photovoltaic performances. Thus, each layer and interface is suited for additive engineering. However, this review focuses on the 'additive' with respect to the perovskite precursor material itself and the resulting changes in the final solid-state films.

Additives related to crystal engineering have been used for some time. The concept of crystal engineering was first introduced by Pepinsky in 1955; it is defined as the understanding of the role of intermolecu-

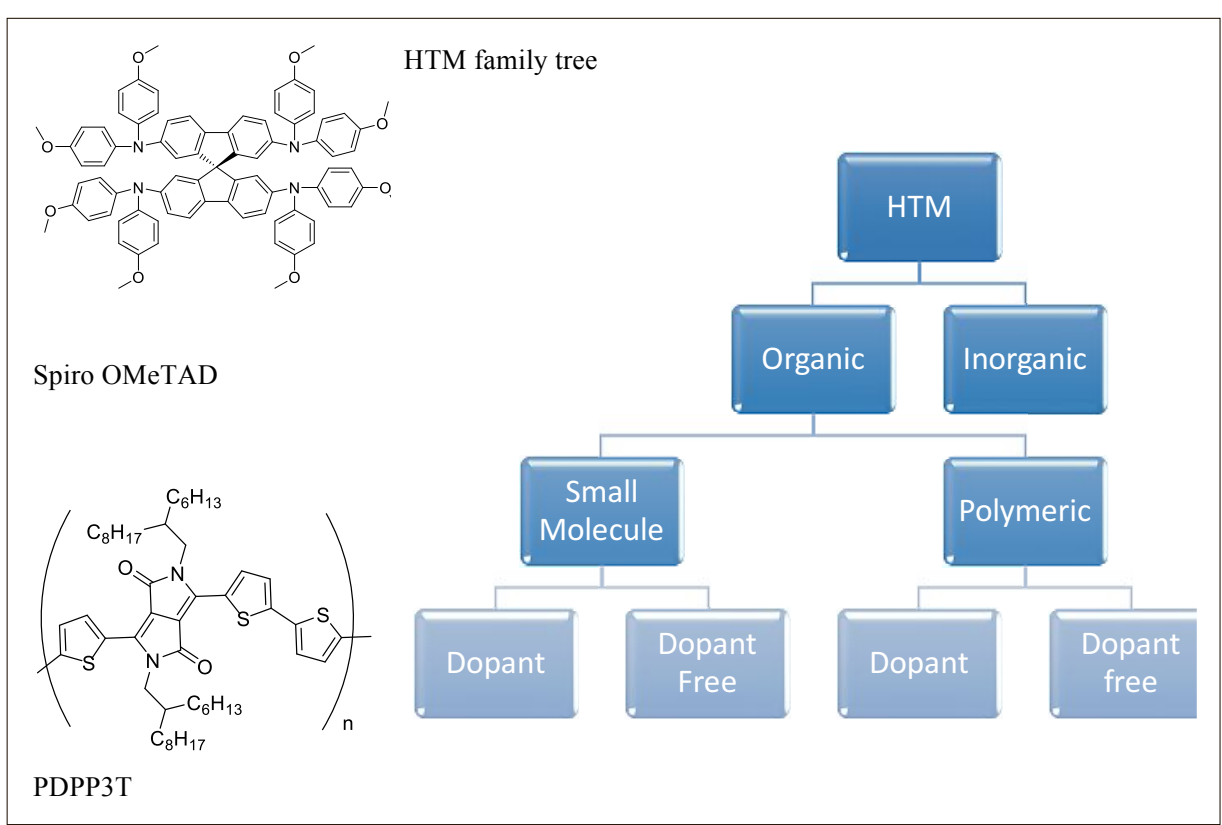

Fig. 1. Hole transporter material (HTM) family tree. 
lar or supramolecular interactions, such as hydrogen bond, van der Waals force, and ionic bonding in crystalline packing. ${ }^{52]}$ As shown in Fig. 2, the perovskite crystal structure consists of octahedral $\mathrm{MX}_{6}$ and organic molecules with $-\mathrm{R}-\mathrm{NH}_{3}$ terminal groups, enabling the establishment of ionic or hydrogen bond interactions. ${ }^{[53]}$ One promising goal for additives in perovskites is the improvement of the crystal quality, or the increase of the grain size in order to prevent performance losses from defects and grain boundaries in the perovskite film.

In principle, a perovskite additive is a good candidate if it contains a common cation or anion with the target perovskite precursor so that its introduction does not disturb the crystal structure significantly. Table 1 summarizes a number of the most recently reported additives together with the respective perovskite precursor, the PCE of the resulting best device, and the main improvement achieved upon additive introduction with respect to efficiency and stability. They are categorized as metal salts, organic salts, and molecules.

There have been many studies on perovskite formulations, ranging from pure $\mathrm{MAPbI}_{3}$ to $\mathrm{MA}_{\mathrm{x}} \mathrm{FA}_{1-\mathrm{x}} \mathrm{PbI}_{3-\mathrm{y}} \mathrm{Br}_{\mathrm{y}}$ by compositional engineering. ${ }^{26,70]}$ Most widely used precursors for these perovskites are

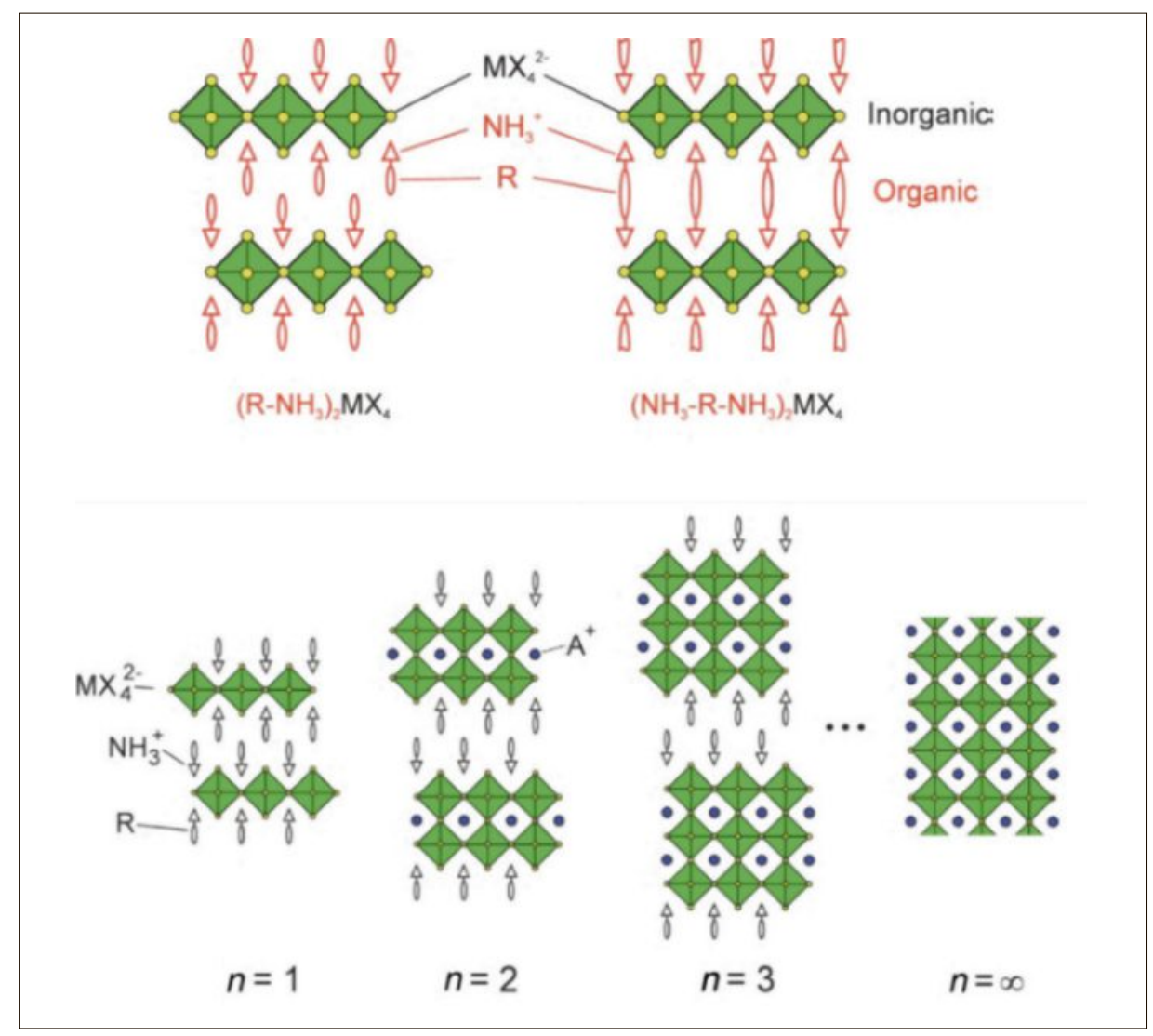

Fig. 2. Scheme of single-layer $<100>$-oriented perovskites with $\mathrm{RNH}_{3}{ }^{+}$and $3 \mathrm{D}$ structure. Reproduced from ref. [53] with permission from The Royal Society of Chemistry.

Table 1. Additives used for perovskite and their corresponding perovskite system with PCEs of devices

\begin{tabular}{|c|c|c|c|c|c|c|c|}
\hline Additive & Pervoskite Precursor & $\begin{array}{l}\mathrm{PCE}^{\mathrm{a}} \\
{[\%]}\end{array}$ & $\begin{array}{l}V_{o c}^{a} \\
{[\mathrm{~V}]}\end{array}$ & $\begin{array}{l}J_{S C}{ }^{\mathrm{a}} \\
{\left[\mathrm{mA} / \mathrm{cm}^{2}\right]}\end{array}$ & Main improvement & Year & Ref. \\
\hline $\mathrm{PbCl}_{2}^{\mathrm{b}}$ & $\mathrm{MAPbI}_{3}$ & 18.1 & 1.04 & 23.5 & Efficiency & 2017 & [54] \\
\hline $\mathrm{Pb}(\mathrm{OAc})_{2}$ & $\mathrm{MAPbI}_{3-\mathrm{x}} \mathrm{Cl}_{\mathrm{x}}$ & 15.2 & 0.97 & 21.7 & Efficiency & 2015 & [55] \\
\hline $\mathrm{Pb}(\mathrm{SCN})_{2}$ & $\mathrm{MA}_{\mathrm{x}} \mathrm{FA}_{1-\mathrm{x}} \mathrm{PbI}_{3}$ & 20.1 & 1.12 & 22.9 & Efficiency & 2017 & [56] \\
\hline $\mathrm{PB}(\mathrm{SCN})_{2}$ & $\mathrm{MAPbI}_{3}$ & 8.3 & 0.87 & 15.1 & Stability & 2015 & [57] \\
\hline $\mathrm{NaI}$ & $\mathrm{MAPbI}_{3-\mathrm{x}} \mathrm{Cl}_{\mathrm{x}}$ & 12.6 & 0.92 & 22.4 & Hysteresis & 2016 & [58] \\
\hline CsI & $\mathrm{MA}_{\mathrm{x}} \mathrm{FA}_{1-\mathrm{x}} \mathrm{Pb}_{3-\mathrm{y}} \mathrm{Br}_{\mathrm{y}}$ & 21.2 & 1.15 & 23.5 & Reproducibility & 2016 & [59] \\
\hline $\mathrm{RbI}$ & $\mathrm{Cs}_{z} \mathrm{MA}_{\mathrm{x}} \mathrm{FA}_{1-\mathrm{x}} \mathrm{Pb}_{3-\mathrm{y}} \mathrm{Br}_{\mathrm{y}}$ & 21.8 & 1.18 & 22.8 & Stability & 2017 & [60] \\
\hline $\mathrm{Cu}$ (thiourea)I & $\mathrm{MAPbI}_{3-\mathrm{x}} \mathrm{Cl}_{\mathrm{x}}$ & 19.9 & 1.13 & 22.3 & Efficiency & 2017 & [61] \\
\hline $\mathrm{MACl}$ & $\mathrm{MAPbI}_{3}$ & 12.1 & 1.02 & 20.4 & Efficiency & 2014 & [62] \\
\hline $\mathrm{MACl}$ & $\mathrm{MAPbI}_{3}$ & 18.55 & 1.08 & 22.2 & Efficiency & 2017 & [63] \\
\hline $\mathrm{MA}\left(\mathrm{COO}^{-}\right)_{2}$ & $\mathrm{MA}_{\mathrm{x}} \mathrm{FA}_{1-\mathrm{x}} \mathrm{PbI}_{3-\mathrm{y}} \mathrm{Cl}_{\mathrm{y}}$ & 19.5 & 1.14 & 22.7 & Efficiency & 2016 & [64] \\
\hline $\mathrm{MA}(\mathrm{OAc})_{2}$ & $\mathrm{MAPbI}_{3}$ & 18.09 & 1.00 & 22.9 & Efficiency & 2017 & [65] \\
\hline $\mathrm{NH}_{4} \mathrm{Ac}$ & $\mathrm{MAPbI}_{3}$ & 17.02 & 1.10 & 22.9 & Efficiency & 2016 & [66] \\
\hline FEAl & $\mathrm{MAPbI}_{3}$ & 18 & 1.06 & 21.2 & Stability & 2016 & [67] \\
\hline 4-ABPACl & $\mathrm{MAPbI}_{3}$ & 16.55 & 1.00 & 22.1 & Stability & 2015 & [68] \\
\hline 1,4-DIB & $\mathrm{MAPbI}_{3-\mathrm{x}} \mathrm{Cl}_{\mathrm{x}}$ & 13.09 & 0.94 & 18.5 & Efficiency & 2015 & [69] \\
\hline
\end{tabular}

aPCE = Power Conversion Efficiency, $\mathrm{V}_{\mathrm{OC}}=$ open-circuit voltage, $\mathrm{J}_{\mathrm{SC}}=$ short-circuit current density were collected from $\mathrm{J}-\mathrm{V}$ curves for champion photovoltaic devices measured under a simulated AM1.5G. Ac $=$ acetate, $\mathrm{FEAI}=1,1,1$-trifluoro-ethyl ammonium iodide, and Oac $=$ acetoxy. ${ }^{\mathrm{b}} \mathrm{Cl}$ is added in the precursor mixture in order to facilitate film growth. However, due to size mismatch with respect to I, it does not enter into the structure of the generated perovskite structure. 
$\mathrm{PbI}_{2}, \mathrm{PbBr}_{2}, \mathrm{MAI}$, FAI, MABr, and FABr. Novel compounds have been obtained by simply replacing anions or cations by means of introducing additives in the perovskite precursor. This affects not only the perovskite structure but also frequently the film morphology because of the interaction during the precursor deposition toward film formation.

For example, as outlined in Fig. 3, it is possible to add $\mathrm{Cl}$ to compounds that contain $\mathrm{Br}$ and/or I. In fact, methylammonium chloride $(\mathrm{MACl})$ was added to $\mathrm{MAPbI}_{3}$ to improve crystal quality and surface coverage of the perovskite film as shown by Zhao et al. and Yang et al. ${ }^{[62,63]}$ Similarly, $\mathrm{MACl}$ and $\mathrm{PbCl}_{2}$ were added to $\mathrm{MAPbI}_{3}$, modifying the morphology of the perovskite film and leading to enhanced electronic properties and dynamics of charge carriers in the $\mathrm{MAPbI}_{3}$ film compared to a pristine $\mathrm{MAPbI}_{3}$ film. ${ }^{354]}$

Recently, there have been many studies using alkali metals ( $\mathrm{Li}, \mathrm{Na}, \mathrm{K}, \mathrm{Rb}, \mathrm{Cs}$ ) as additives. This is motivated by considering the tolerance factor, which is defined as:

$$
t=\frac{r_{A}+r_{I}}{\sqrt{2}\left(r_{P b}+r_{I}\right)}
$$

(where $\mathrm{r}$ are the ionic radii in an $\mathrm{APbI}_{3}$ perovskite). Empirically, perovskites that have a photoactive black phase fulfil the relation $0.8<t<1.0 .{ }^{[60]}$ The tolerance factor shows that, with respect to the alkali metal cations, only $\mathrm{CsPbI}_{3}$ falls into the range of photoactive perovskites with an $\alpha$-phase (black phase). Related Li, Na, and K-based materials are clearly outside of the range, whereas $\mathrm{RbPbI}_{3}$ only misses this requirement by a small margin.

Saliba et al. investigated the addition of inorganic cesium to $\mathrm{MA}_{\mathrm{x}} \mathrm{FA}_{1-\mathrm{x}} \mathrm{PbI}_{3-\mathrm{y}} \mathrm{Br}_{\mathrm{y}}$. The resulting triple-cation perovskite compositions are thermally more stable, contain fewer phase impurities, and are less sensitive to processing conditions. ${ }^{[8]}$ Upon addition of small amounts of Cs from 0,5 , 10 , and $15 \%$, the yellow phase and the $\mathrm{PbI}_{2}$ peak disappear completely as shown in Fig. 4a. Moreover, a small addition of Cs, up to $15 \%$, blue-shifts the band gap of the material by $\sim 10 \mathrm{~nm}$, as deduced from the absorption onset and photoluminescence (PL) spectra (Fig. 4b). The Cs also helps to stabilize the black phase of perovskite and increase the crystallinity according to Figs $4 \mathrm{c}$ and $4 \mathrm{~d}$. As demonstrated by XRD spectra, the triple cation mixture forms the perovskite phase even without any annealing, as shown by the peak at $\sim 14^{\circ}$. These triple cation perovskites paved the way to a substantial improvement of the quality of the perovskite solar cells in terms of reproducibility, with PCEs over $20 \%$ reached on a regular basis.

Subsequently, Saliba et al. reported that $\mathrm{RbI}$ added to the previously developed Cs-containing perovskite, and all other FA containing combinations such as RbFA, RbCsFA, RbMAFA, shows high PSC performance with stabilized efficiency of $21.6 \%$ at $977 \mathrm{mV}$ and $22.1 \mathrm{~mA} / \mathrm{cm}^{2}$ together with remarkable stability; $95 \%$ of their initial performance is maintained at $85^{\circ} \mathrm{C}$ for 500 hours under illumination and maximum power-point tracking. ${ }^{60]}$

Very recently, the Bian group reported the use of copper iodide (CuI) and its derivative $\mathrm{Cu}$ (thiourea)I as an additive to the $\mathrm{MAPbI}_{3-x} \mathrm{Cl}_{\mathrm{x}}$ perovskite, which results in the efficient passivation of trap states of the perovskite via interaction between the under-coordinated metal cations and halide anions at the perovskite crystal surface. A PCE of $19.9 \%$ was achieved. [61]

Formate and acetate anion compounds, with similar or slightly larger molecular size compared to halides, have been studied by several groups. ${ }^{[55,64-66]}$ Methylammonium formate (MAF) was added to perovskite by $\mathrm{Seo}$ et al. for inhibiting the $\mathrm{Pb}^{+}-\mathrm{I}$ interaction during crystal formation. The role of MAF is illustrated in Fig. 5a. Adding

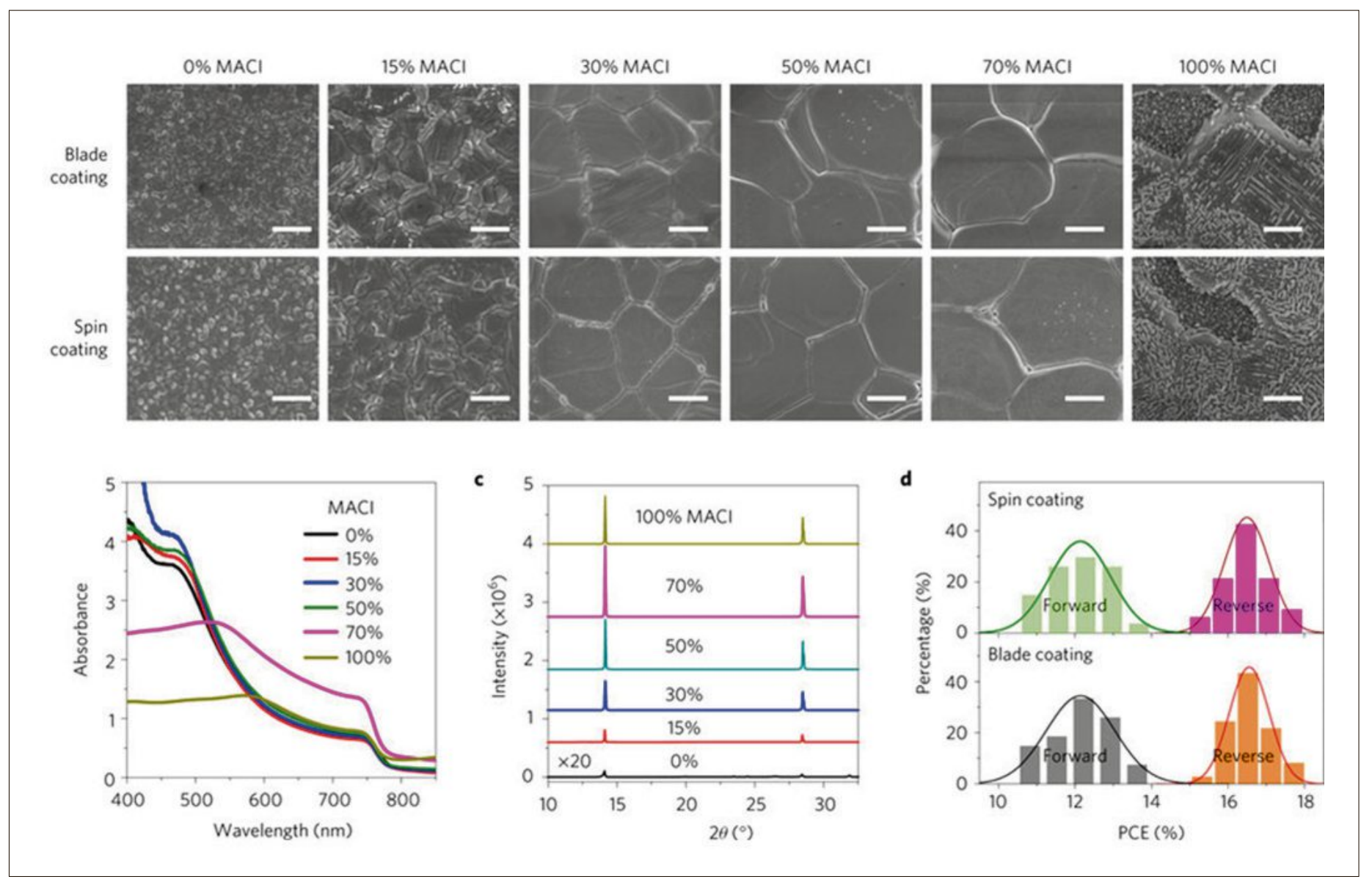

Fig. 3. The effect of chloride additives: MACl. Reproduced with permission from ref. [12] with permission of Macmillan Publishers Ltd. on perovskite morphology and film properties. 

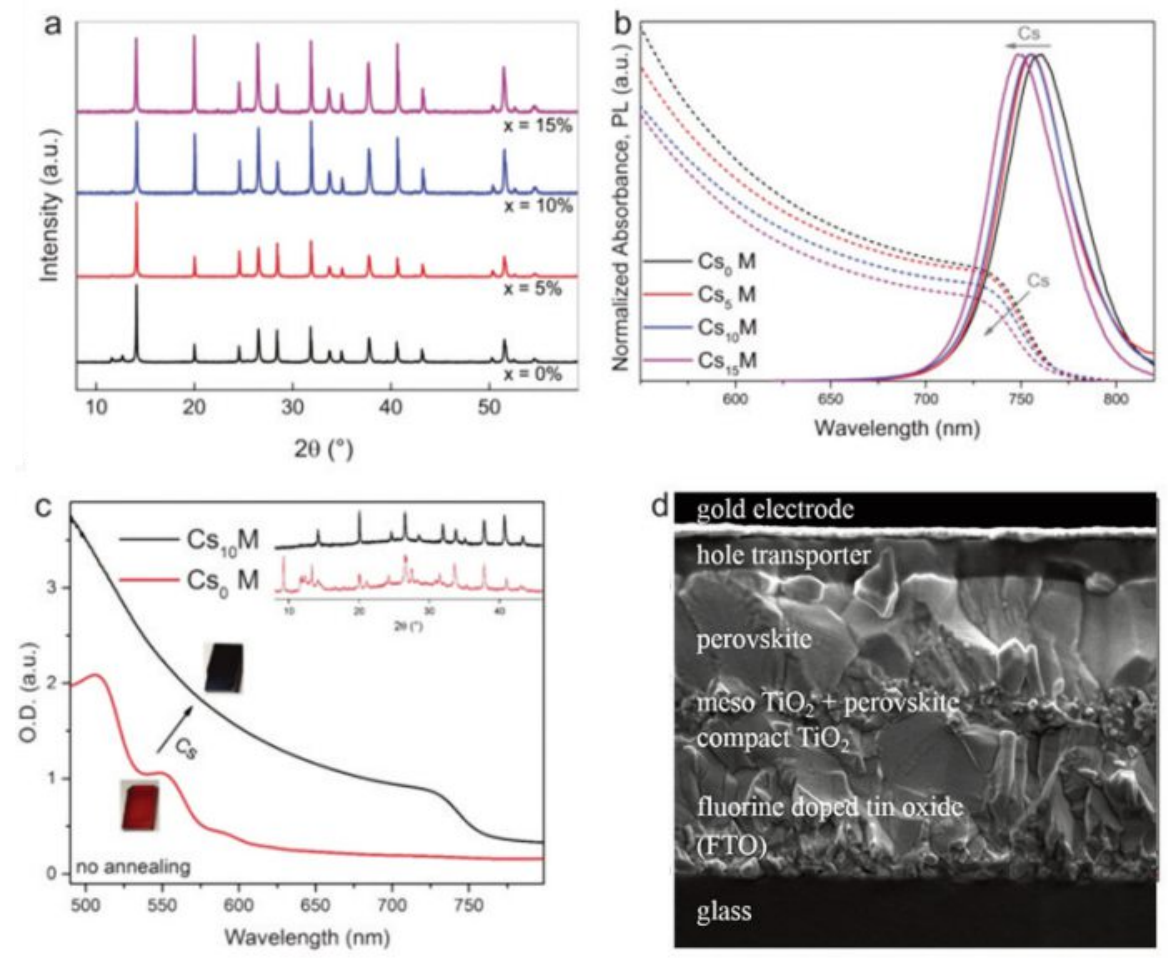

Fig. 4. (a) XRD spectra and (b) absorbance and photoluminescence (PL) spectra of cesium, referring to the series $\mathrm{Cs}_{x}\left(\mathrm{MA}_{0.17} \mathrm{FA}_{0.83}\right)_{(1-x)} \mathrm{Pb}\left(\mathrm{I}_{0.83} \mathrm{Br}_{0.17}\right)_{3}$ of annealed perovskite films; (c) absorbance and $\mathrm{X}$-ray diffraction (XRD) spectra at room temperature (without subsequent annealing) of prepared perovskite films; (d) cross-sectional SEM image of photovoltaic devices with $5 \%$ Cs perovskite. Reproduced from ref. [59] with permission of The Royal Society of Chemistry.

MAF results in slower crystal growth and larger grain size of the perovskite film after annealing (Fig. 5b). ${ }^{[64]}$

Additives enhance not only the efficiency but also the stability of perovskite solar cells. For instance, amphiphilic additives such as 1,1,1-trifluoro-ethylammonium iodide (FEAI) and butylphosphoric acid 4-ammonium chloride (4-ABPACl $)^{[67,68]}$ enhanced the perovskite stability. This kind of additives containing bifunctional group (ammonium and phosphoric acid groups) can provide interparticle bridging, which assists in the formation of uniform perovskite films and enhances the stability of the perovskite layer and the resulting PSCs.

In addition to salt-type molecules, alkyl halide additives have been studied by Jen Liang et al.[69] Their study showed that the crystallization of a solution-processed perovskite can be controlled by incorporating additives like 1,8-diiodooctane (DIO) into its precursor solution to modulate thin film formation (Fig. 6a). The capacity of bidentate-halogenated additives to temporarily chelate $\mathrm{Pb}^{2+}$ during crystal growth (Fig. 6b) and the ensuing inhibition encourage homogenous nucleation and lead to improved film morphology and device performance.

\section{Spectroscopic Characterization of Perovskites}

Numerous spectroscopic characterization techniques have been employed to study perovskite materials. In particular, steady state measurements have been widely used as they are rapid, contactless and non-destructive. The techniques that are centred on studying the absorption and emission characteristics of perovskite films will be taken up in this review, with focus on the latter. Techniques described here include UV-Vis spectroscopy, steadystate and time-resolved photoluminescence (PL) spectroscopy, PL mapping and Raman spectroscopy.

\section{Absorption}

Absorption spectra have been extensively used to determine the range over which light is absorbed for various semiconductor materials. Of particular interest are the onset of light absorption and the peak maximum. They have been equally useful in recent studies of organic-inorganic perovskites. ${ }^{[71]}$ Nevertheless, some challenges seem to arise while measuring the UV-Vis spectra of perovskite films, as described by Tian et al. ${ }^{[72]}$

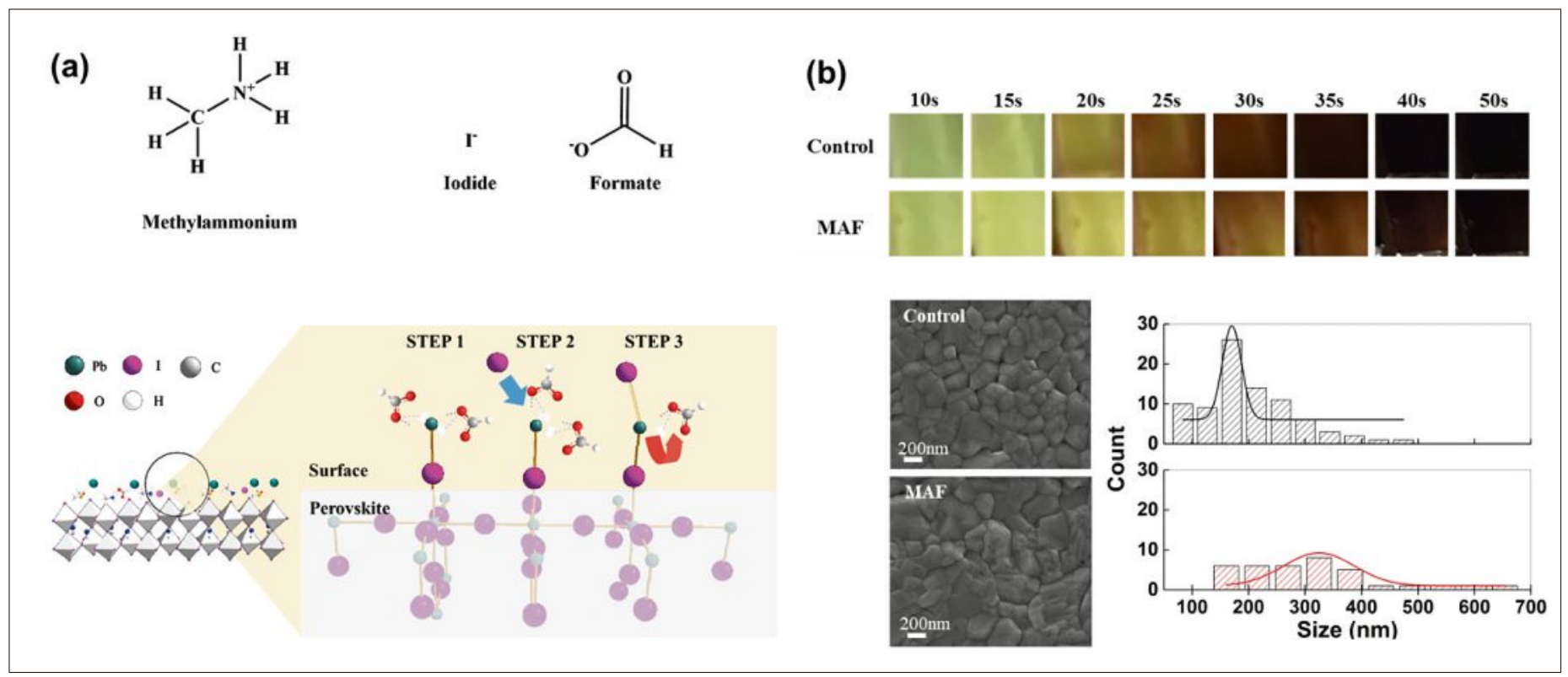

Fig. 5. (a) Schematic of the proposed perovskite crystal growth mechanism as controlled by the formate anions; (b) morphological analysis of the perovskite films with and without MAF. Reproduced from ref. [64] with permission from WILEY-VCH Verlag GmbH \& Co. KGaA, Weinheim. 
(a)

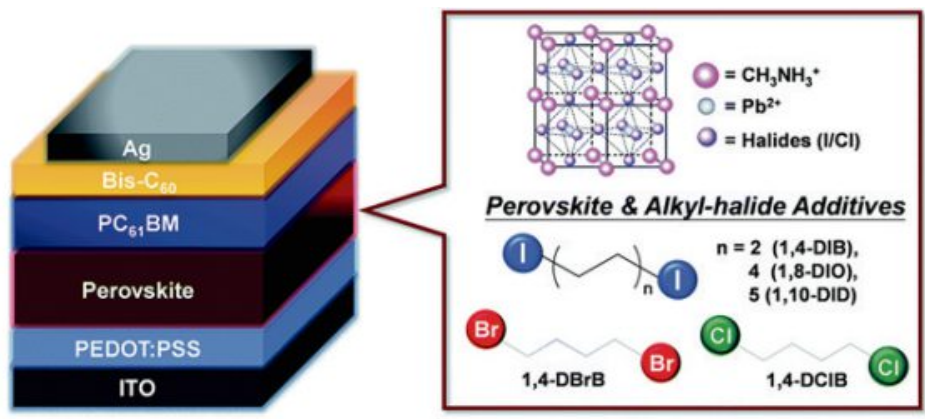

(b)

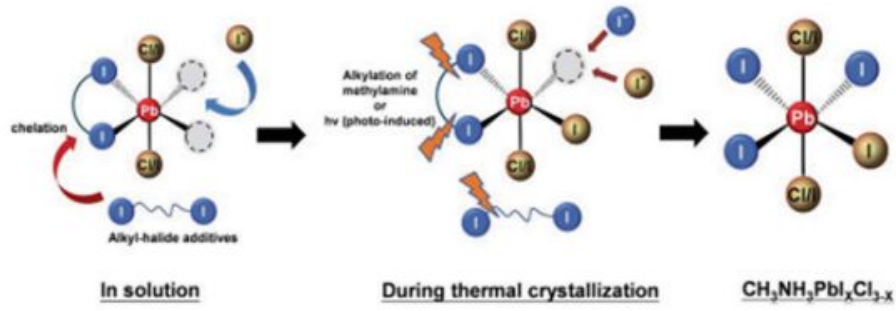

Fig. 6. (a) Molecular structure of alkyl halide additives; (b) schematic diagram for the transient chelation of $\mathrm{Pb}^{2+}$ with additives. Reproduced from ref. [69] with permission from The Royal Society of Chemistry.

The work by De Wolf et al.[71] discusses the interesting implications of the sharp optical absorption edge present in perovskites for photovoltaic performance. In particular, they plotted the absorption coefficient as a function of photon energy for typical photovoltaic materials, including perovskites and identified the presence of absorption tail states, also called the Urbach tail. They took a closer look at these absorption tail states by extracting the Urbach energy, which is the slope of the exponential part of the above mentioned plot. An increase in the Urbach energy is indicative of the structural disorder of the semiconductor, a crucial aspect of materials used in opto-electronic applications. ${ }^{[71]}$ De Wolf et al. also reported that the $\mathrm{CH}_{3} \mathrm{NH}_{3} \mathrm{PbI}_{3}$ perovskite has a steep absorption onset, giving an Urbach energy as small as $15 \mathrm{meV}$, which points to a well-ordered microstructure.

The use of additives in the preparation of perovskite films has been discussed earlier. Zhang et al. ${ }^{[73]}$ demonstrated the use of hypophosphorous acid as an additive to improve perovskite film quality. They showed that the Urbach energy is lower for the film with the hypophosphorous acid due to better electronic order in the material.

\section{Emission}

Due to the large potential of perovskites for use in opto-electronic applications, including photovoltaics and light emitting diodes, understanding the emission behaviour of these materials is of considerable importance. ${ }^{[74]}$ Researchers often use photoluminescence measurements to evaluate the quality of perovskite films ${ }^{[75]}$ and solar cells. ${ }^{[74]}$

\section{Steady-state Photoluminescence Spectroscopy}

One of the most commonly used measurements is steady-state PL (see Fig. 7a), which can provide information complementary to the absorption spectra discussed earlier. Steady-state PL is a convenient option for the swift detection of perovskites of various compositions, thereby different bandgaps, as evident from the report by McMeekin et al. ${ }^{[76]}$ Furthermore, as highly luminescent films are associated with superior film quality, ${ }^{[77]}$ the measurement can be used to assess and compare perovskite films.

In addition, steady-state PL measurements have been used in the literature to investigate the HTM/perovskite interface.
Zhang et al. ${ }^{[78]}$ studied $\mathrm{CH}_{3} \mathrm{NH}_{3} \mathrm{PbI}_{3}$ perovskite films with different HTMs deposited on top. They found that more than $90 \%$ of the PL was quenched when suitable HTMs such as spiro-OMeTAD were used, indicating that efficient charge transfer takes place across the interface, from the perovskite to the HTM.

\section{Time-resolved Photoluminescence Spectroscopy}

Time-correlated single photon counting can be used to study the photo-physical properties of perovskite films and crystals. The recombination lifetime of charge carriers can be measured using this technique. Longer lifetimes are often associated with superior material quality. ${ }^{[75]}$ Several reports in the literature have utilized this technique to compare control samples with those containing additives. ${ }^{[61,73]}$ Many have demonstrated that superior film quality, achieved through the inclusion of additives, is associated with longer recombination lifetimes.

Studies have also focused on employing PL decay measurements to explain the kinetics of recombination in organic-inorganic perovskites. ${ }^{[79]}$ In addition, charge-carrier diffusion constants and diffusion lengths can be assessed using different charge-transport layers through the quenching observed in the PL decay. ${ }^{[80]}$

\section{Photoluminescence Mapping}

PL mapping is an important imaging tool frequently used in biology, and recently adopted in geology. In this technique, the local emission can be probed pointby-point, thereby generating a two-dimensional map. ${ }^{\left[{ }^{81]}\right.}$ It has also been successfully employed to characterize perovskite films (see Fig. 7b). In the study by de Quilettes et al., ${ }^{[75]}$ it was employed to demonstrate that grains in perovskite films exhibit different PL intensities and lifetimes, in spite of the fact that these films had long bulk lifetimes. Mastroianni et al. ${ }^{[74]}$ looked into

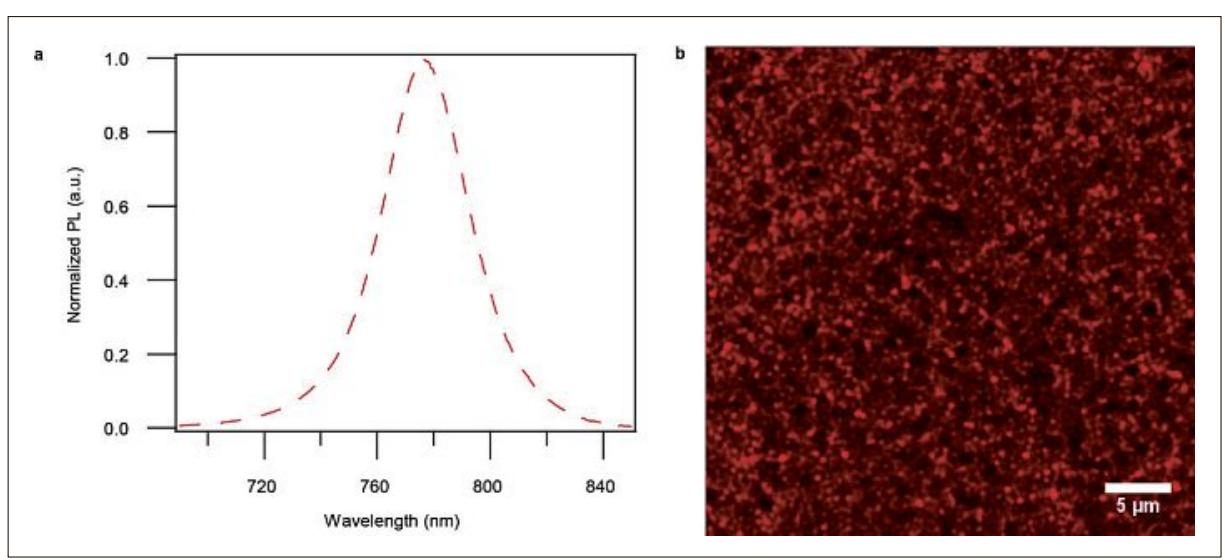

Fig. 7. Spectroscopic characterization of a $\mathrm{CH}_{3} \mathrm{NH}_{3} \mathrm{Pbl}_{3}$ perovskite film. (a) Normalized PL spectrum. (b) PL map of the surface showing the emission between 700 and $800 \mathrm{~nm}$ attributed to the perovskite, assigned the colour red. Colour saturation scales with emission intensity. 
the correlation of the morphology of perovskite films with the photovoltaic performance using this technique. It was also used to show the photo-brightening of perovskite films, resulting in enhanced PL. ${ }^{\left[{ }^{82]}\right.}$

As this tool facilitates the localization of different components based on differences in their emission wavelengths, it has also been used to study the formation of perovskite films in sequential deposition ${ }^{[83]}$ and in the anti-solvent method. ${ }^{[60]}$ Therefore, it has the potential to answer interesting questions that are more challenging to address, necessitating the use of techniques frequently employed in material science such as scanning electron microscopy and atomic-force microscopy.

\section{Raman Spectroscopy}

Several researchers have investigated the application of Raman spectroscopy in perovskite materials. Quarti et al. ${ }^{[84]}$ have published the Raman spectra of $\mathrm{CH}_{3} \mathrm{NH}_{3} \mathrm{PbI}_{3}$. Ledinsky et al. ${ }^{[85]}$ have shown that such measurements can be used to evaluate the composition of perovskite mixtures, demonstrating the case of changing $x(0 \leq x \leq 1)$ in $\mathrm{CH}_{3} \mathrm{NH}_{3} \mathrm{~Pb}\left(\mathrm{I}_{x} \mathrm{Br}_{1-x}\right)_{3}$. However, the degradation of the perovskites during measurement should be carefully avoided as described in the literature. ${ }^{[71]}$

\section{Summary and Outlook}

The emerging field of PSCs provides inexpensive, abundant materials that were optimized to reach peak efficiencies of $22 \%$ in just a few years. This is unprecedented for the photovoltaic research community and the next years will show if the promise of inexpensive, sustainable energy from PSCs can be turned into reality through commercialization. For this, major advances in stability are needed so that PSCs can withstand outdoor conditions for many years similar to the performance currently shown by silicon solar cells. Here, progress is needed in terms of the HTMs that we use in perovskite solar cells as we need additional functionality beyond charge transport to protect the perovskite layer. In addition, the perovskite layer itself needs fortification through means such as the addition of ionic liquids and inorganic salts. The modified perovskite films need to be characterised throughout the optimisation process to understand not only the precise film formation mechanism and the final film properties, but also the long-term degradation mechanisms taking place. These advances would play a key role in clearing several roadblocks in the commercialization of PSCs.

\section{Acknowledgements}

Financial support was provided by the Swiss National Science Foundation through grant no. 200021-157135/1. MG and SMZ thank the Swiss National Science Foundation (SNF)NRP70 'Energy Turnaround' and the King Abdulaziz City for Science and Technology (KACST) for financial support under a joint research project.

\section{Received: August 21, 2017}

[1] W. S. Yang, B.-W. Park, E. H. Jung, N. J. Jeon, Y. C. Kim, D. U. Lee, S. S. Shin, J. Seo, E. K. Kim, J. H. Noh, S. Il Seok, Science 2017, 356, 1376.

[2] A. Kojima, K. Teshima, Y. Shirai, T. Miyasaka, J. Am. Chem. Soc. 2009, 131, 6050.

[3] D. Weber, Zeit. Naturforsch. B 1978, 33, 1443.

[4] D. Weber, Zeit. Naturforsch. B 1978, 33, 862.

[5] T. Ishihara, J. Takahashi, T. Goto, Phys. Rev. B 1990, 42, 11099.

[6] T. Ishihara, J. Lumin. 1994, 60-61, 269.

[7] M, Era, T. Hattori, T. Taira, T. Tsutsui, Chem Mater. 1997, 9, 8.

[8] K. Tanaka, T. Takahashi, T. Kondo, K. Umeda, K. Ema, T. Umebayashi, K. Asai, K. Uchida, N. Miura, Jpn. J. Appl. Phys. 2005, 44, 5923.

[9] G. C. Papavassiliou, Mol. Cryst. Liq. Cryst. Sci. Technol. Sect. A. Mol. Cryst. Liq. Cryst. 1996, 286, 231.

[10] D. B. Mitzi, Prog. Inorg. Chem. 1991, 48, 1.

[11] T. Kondo, T. Azuma, T. Yuasa, R. Ito, Solid State Commun. 1998, 105, 253.

[12] M. Yang, Z. Li, M. O. Reese, O. G. Reid, D. H. Kim, S. Siol, T. R. Klein, Y. Yan, J. J. Berry, M F. A. M. van Hest, K. Zhu, Nat. Energy 2017, 2, 17038.

[13] J.-H. Im, C.-R. Lee, J.-W. Lee, S.-W. Park, N.G. Park, Nanoscale 2011, 3, 4088

[14] H.-S. Kim, C.-R. Lee, J.-H. Im, K.-B. Lee, T Moehl, A. Marchioro, S.-J. Moon, R. HumphryBaker, J.-H. Yum, J. E. Moser, M. Grätzel, N. G. Park, Sci. Rep. 2012, 2, 591.

[15] J. M. Ball, M. M. Lee, A. Hey, H. J. Snaith, Energy Environ. Sci. 2013, 6, 1739.

[16] M. M. Lee, J. Teuscher, T. Miyasaka, T. N. Murakami, H. J. Snaith, Science 2012, 338 , 643

[17] L. Calió, S. Kazim, M. Grätzel, S. Ahmad, Angew. Chem. Int. Ed. 2016, 55, 14522.

[18] P. Gao, M. Grätzel, M. K. Nazeeruddin, Energy Environ. Sci. 2014, 7, 2448.

[19] R. Gottesman, A. Zaban, Acc. Chem. Res. 2016, $49,320$.

[20] M. A. M. A. Green, A. Ho-Baillie, H. J. H. J. J. Snaith, Nat. Photonics 2014, 8, 506.

[21] N. Marinova, S. Valero, J. L. J. L. Delgado, $J$ Colloid Interface Sci. 2017, 488, 373.

[22] T. Miyasaka, J. Phys. Chem. Lett. 2011, 2, 262.

[23] T. Miyasaka, Chem. Lett. 2015, 44, 720.

[24] T. Singh, J. Singh, T. Miyasaka, Chem. Sus. Chem. 2016, 9, 2559.

25] H. J. Snaith, J. Phys. Chem. Lett. 2013, 4, 3623.

[26] S. D. S. D. Stranks, H. J. H. J. Snaith, Nat. Nanotechnol. 2015, 10, 391.

[27] J.-P. Correa-Baena, A. Abate, M. Saliba, W. Tress, T. Jesper Jacobsson, M. Grätzel, A Hagfeldt, Energy Environ. Sci. 2017, 10, 710.

[28] M. Saliba, J.-P. Correa-Baena, M. Graetzel, A. Hagfeldt, A. Abate, Angew. Chemie Int. Ed. 2017, DOI: $10.1002 /$ anie. 201703226.

[29] P. Qin, S. Tanaka, S. Ito, N. Tetreault, K Manabe, H. Nishino, M. K. Nazeeruddin, M. Grätzel, Nat. Commun. 2014, 5, 3834.

[30] S. F. S. F. Völker, S. Collavini, J. L. J. L. Delgado, ChemSusChem 2015, 8, 3012.

[31] A. Isakova, P. D. Topham, J. Polym. Sci. Part B Polym. Phys. 2017, 55, 549.
[32] Y.-K. Wang, Z.-Q. Jiang, L.-S. Liao, Chinese Chem. Lett. 2016, 27, 1293

[33] J. Zhang, B. Xu, L. Yang, A. Mingorance, C. Ruan, Y. Hua, L. Wang, N. Vlachopoulos, M. Lira-Cantú, G. Boschloo, A. Hagfeldt, L. Sun, E. M. J. Johansson, Adv. Energy Mater. 2017, 1602736.

[34] J. Liu, Y. Wu, C. Qin, X. Yang, T. Yasuda, A. Islam, K. Zhang, W. Peng, W. Chen, L. Han, Energy Environ. Sci. 2014, 7, 2963.

[35] Z. H. Bakr, Q. Wali, A. Fakharuddin, L. Schmidt-Mende, T. M. Brown, R. Jose, Nano Energy 2017, 34, 271.

[36] J. Salbeck, N. Yu, J. Bauer, F. Weissörtel, H. Bestgen, Synth. Met. 1997, 91, 209.

[37] J. Salbeck, F. Weissörtel, J. Bauer, Macromol. Symp. 1998, 125, 121.

[38] T. C. Parker, S. R. Marder, 'Synthetic methods in organic electronic and photonic materials : a practical guide', The Royal Society of Chemistry. Cambridge, 2015.

[39] J.-R. Pouliot, F. Grenier, J. T. Blaskovits, S. Beaupré, M. Leclerc, Chem. Rev. 2016, 116, 14225.

[40] T. Leijtens, I-K. Ding, T. Giovenzana, J. T. Bloking, M. D. McGehee, A. Sellinger, ACS Nano 2012, 6, 1455.

[41] U. Bach, D. Lupo, P. Comte, J. E. Moser, F. Weissörtel, J. Salbeck, H. Spreitzer, M. Grätzel, Nature 1998, 395, 583

[42] N. J. Jeon, H. G. Lee, Y. C. Kim, J. Seo, J. H. Noh, J. Lee, S. Il Seok, J. Am. Chem. Soc. 2014, 136, 7837.

[43] H. J. Snaith, M. Grätzel, Appl. Phys. Lett. 2006 89,262114

[44] X. Zhao, F. Zhang, C. Yi, D. Bi, X. Bi, P. Wei, J. Luo, X. Liu, S. Wang, X. Li, S. M. Zakeeruddin, M. Grätzel, D. Li, X. Li, Q. Meng, J. Mater. Chem. A 2016, 4, 16330.

[45] B. Xu, D. Bi, Y. Hua, P. Liu, M. Cheng, M. Grätzel, L. Kloo, A. Hagfeldt, L. Sun, Energy Environ. Sci. 2016, 9, 873.

[46] A. Krishna, D. Sabba, J. Yin, A. Bruno, L. J. Antila, C. Soci, S. Mhaisalkar, A. C. Grimsdale, W. Chen, L. Han, A. Hagfeldt, M. Grätzel, M. K. Nazeeruddin, J. Mater. Chem. A 2016, 4, 8750

[47] M. Grzybowski, D. T. Gryko, Adv. Opt. Mater 2015, 3, 280

[48] Y. Li, P. Sonar, L. Murphy, W. Hong, T. D Anthopoulos, M. Heeney, D. Zhu, K. Song, S. E. Watkins, Y. Geerts, M. M. Wienk, R. A. J. Janssen, T. Anthopoulos, H. Sirringhaus, M. Heeney, I. McCulloch, Energy Environ. Sci. 2013, $6,1684$.

[49] X. Liu, F. Kong, Z. Tan, T. Cheng, W. Chen, T. Yu, F. Guo, J. Chen, J. Yao, S. Dai, $R S C A d v$. 2016, 6, 87454

[50] A. Dubey, N. Adhikari, S. Venkatesan, S. Gu, D. Khatiwada, Q. Wang, L. Mohammad, M. Kumar, Q. Qiao, Sol. Energy Mater. Sol. Cells 2016, $145,193$.

[51] H.-C. Liao, T. L. D. Tam, P. Guo, Y. Wu, E. F. Manley, W. Huang, N. Zhou, C. M. M. Soe, B. Wang, M. R. Wasielewski, L. X. Chen, M. G. Kanatzidis, A. Facchetti, R. P. H. Chang, T. J. Marks, Adv. Energy Mater. 2016, 6 , 1600502

[52] G. R. Desiraju, J. J. Vittal, A. Ramanan, 'Crystal Engineering: a Textbook', World Scientific, Singapore, 2011

[53] D. B. Mitzi, J. Chem. Soc. Dalt. Trans. 2001, 1 , DOI: 10.1039/B007070J

[54] N. D. Pham, V. T. Tiong, P. Chen, L. Wang, G. J. Wilson, J. Bell, H. Wang, J. Mater. Chem. A 2017, 5, 5195 .

[55] W. Zhang, M. Saliba, D. T. Moore, S. K. Pathak, M. T. Horantner, T. Stergiopoulos, S. D. Stranks, G. E. Eperon, J. A. Alexander-Webber, A. Abate, A. Sadhanala, S. Yao, Y. Chen, R. H. Friend, L. A. Estroff, U. Wiesner, H. J. Snaith, Nat Commun 2015, 6, 6142. 
[56] C. Wang, D. Zhao, Y. Yu, N. Shrestha, C. R Grice, W. Liao, A. J. Cimaroli, J. Chen, R. J. Ellingson, X. Zhao, Y. Yan, Nano Energy 2017, 35, 223.

[57] Q. Jiang, D. Rebollar, J. Gong, E. L. Piacentino, C. Zheng, T. Xu, Angew. Chem. Int. Ed. 2015, 54, 7617.

[58] L. Wang, D. Moghe, S. Hafezian, P. Chen, M. Young, M. Elinski, L. Martinu, S. Kéna-Cohen, R. R. Lunt, ACS Appl. Mater. Interfaces 2016, 8, 23086.

[59] M. Saliba, T. Matsui, J.-Y. Seo, K. Domanski, J.-P. Correa-Baena, M. K. Nazeeruddin, S. M. Zakeeruddin, W. Tress, A. Abate, A. Hagfeldt, M. Grätzel, Energy Environ. Sci. 2016, 9, 1989.

[60] M. Saliba, T. Matsui, K. Domanski, J.-Y. Seo, A Ummadisingu, S. M. Zakeeruddin, J.-P. CorreaBaena, W. R. Tress, A. Abate, A. Hagfeldt, M Gratzel, Science 2016, 354, 206.

[61] S. Ye, H. Rao, Z. Zhao, L. Zhang, H. Bao, W. Sun, Y. Li, F. Gu, J. Wang, Z. Liu, Z. Bian, C. Huang, J. Am. Chem. Soc. 2017, DOI: 10.1021/ jacs.7b01439.

[62] Y. Zhao, K. Zhu, J. Phys. Chem. C 2014, 118, 9412

[63] M. Yang, Z. Li, M. O. Reese, O. G. Reid, D. H Kim, S. Siol, T. R. Klein, Y. Yan, J. J. Berry, M. F. A. M. van Hest, K. Zhu, Nat. Energy 2017, 2, 17038.

[64] J. Y. Seo, T. Matsui, J. Luo, J. P. CorreaBaena, F. Giordano, M. Saliba, K. Schenk, A Ummadisingu, K. Domanski, M. Hadadian, A Hagfeldt, S. M. Zakeeruddin, U. Steiner, M. Grätzel, A. Abate, Adv. Energy Mater. 2016, 6 , 1600767.
[65] Y. Xia, C. Ran, Y. Chen, Q. Li, N. Jiang, C. Li, Y. Pan, T. Li, J. Wang, W. Huang, J. Mater Chem. A 2017, 5, 3193.

[66] Q. Wu, P. Zhou, W. Zhou, X. Wei, T. Chen, S. Yang, ACS Appl Mater Interfaces 2016, 8, 15333.

[67] D. Bi, P. Gao, R. Scopelliti, E. Oveisi, J. Luo, M. Grätzel, A. Hagfeldt, M. K. Nazeeruddin, Adv. Mater. 2016, 28, 2910.

[68] X. Li, M. I. Dar, C. Yi, J. Luo, M. Tschumi, S. M. Zakeeruddin, M. K. Nazeeruddin, H. Han, M. Gratzel, Nat Chem 2015, 7, 703.

[69] C.-C. Chueh, C.-Y. Liao, F. Zuo, S. T. Williams, P.-W. Liang, A. K.-Y. Jen, J. Mater. Chem. A 2015, 3, 9058 .

[70] N. J. Jeon, J. H. Noh, W. S. Yang, Y. C. Kim, S. Ryu, J. Seo, S. Il Seok, Nature 2015, 517, 476.

[71] S. De Wolf, J. Holovsky, S.-J. Moon, P. Löper, B. Niesen, M. Ledinsky, F.-J. Haug, J.-H. Yum, C. Ballif, J. Phys. Chem. Lett. 2014, 5, 1035.

[72] Y. Tian, I. G. Scheblykin, J. Phys. Chem. Lett. 2015, 6, 3466.

[73] W. Zhang, S. Pathak, N. Sakai, T. Stergiopoulos, P. K. Nayak, N. K. Noel, A. A. Haghighirad, V. M. Burlakov, D. W. deQuilettes, A. Sadhanala, W. Li, L. Wang, D. S. Ginger, R. H. Friend, H. J. Snaith, Nat. Commun. 2015, 6, 10030.

[74] S. Mastroianni, F. D. Heinz, J.-H. Im, W. Veurman, M. Padilla, M. C. Schubert, U. Würfel, M. Grätzel, N.-G. Park, A. Hinsch, Nanoscale 2015, 19653.

[75] D. W. de Quilettes, S. M. Vorpahl, S. D. Stranks, H. Nagaoka, G. E. Eperon, M. E. Ziffer, H. J. Snaith, D. S. Ginger, Science 2015, 348, 683.
[76] D. P. McMeekin, G. Sadoughi, W. Rehman, G. E. Eperon, M. Saliba, M. T. Horantner, A. Haghighirad, N. Sakai, L. Korte, B. Rech, M. B. Johnston, L. M. Herz, H. J. Snaith, Science 2016, 351, 151.

[77] F. Deschler, M. Price, S. Pathak, L. E. Klintberg, D.-D. Jarausch, R. Higler, S. Hüttner, T. Leijtens, S. D. Stranks, H. J. Snaith, M. Atatüre, R. T. Phillips, R. H. Friend, J. Phys. Chem. Lett. 2014, 5, 1421.

[78] F. Zhang, X. Yang, M. Cheng, J. Li, W. Wang, H. Wang, L. Sun, N.-G. Park, Y. Yang, M. A Grover, E. Reichmanis, Q. Meng, J. Mater. Chem. A 2015, 3, 24272.

[79] S. D. Stranks, V. M. Burlakov, T. Leijtens, J. M. Ball, A. Goriely, H. J. Snaith, Phys. Rev. Appl. 2014, 2, 34007.

[80] S. D. Stranks, G. E. Eperon, G. Grancini, C. Menelaou, M. J. P. Alcocer, T. Leijtens, L. M. Herz, A. Petrozza, H. J. Snaith, Science 2013, $342,341$.

[81] J. Kus, Int. J. Coal Geol. 2015, 137, 1.

[82] D. W. deQuilettes, W. Zhang, V. M. Burlakov, D. J. Graham, T. Leijtens, A. Osherov, V. Bulovic, H. J. Snaith, D. S. Ginger, S. D. Stranks, Nat. Commun. 2016, 7, 11683.

[83] A. Ummadisingu, L. Steier, J.-Y. Seo, T. Matsui, A. Abate, W. Tress, M. Grätzel, Nature 2017, 1, DOI: 10.1038/nature22072.

[84] C. Quarti, G. Grancini, E. Mosconi, P. Bruno, J. M. Ball, M. M. Lee, H. J. Snaith, A. Petrozza, F. De Angelis, J. Phys. Chem. Lett. 2014, 5, 279.

[85] M. Ledinský, P. Löper, B. Niesen, J. Holovský, S.-J. Moon, J.-H. Yum, S. De Wolf, A. Fejfar, C. Ballif, J. Phys. Chem. Lett. 2015, 6, 401. 